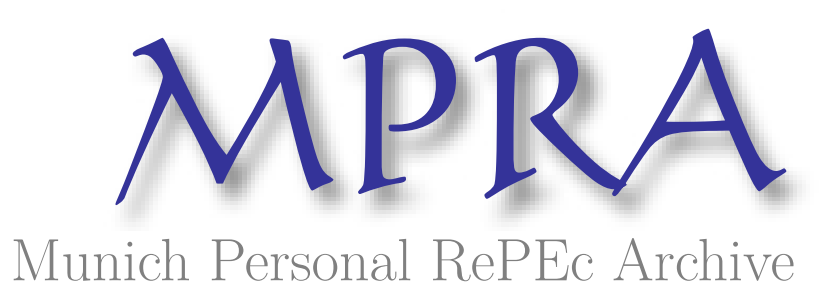

\title{
The formation of offer prices in farmland markets: A hedonic price approach
}

Temel, Tugrul

Development Research Institute (IVO), Tilburg University

29 June 2011

Online at https://mpra.ub.uni-muenchen.de/31921/

MPRA Paper No. 31921, posted 29 Jun 2011 16:54 UTC 


\title{
The Formation of Offer Prices in Farmland Markets:
}

\author{
A Hedonic Price Approach
}

\author{
Edmund M. Tavernier \\ Farong Li \\ Tugrul Temel (t.temel@uvt.nl)
}

June 28, 2011

\begin{abstract}
This study develops a game-theoretic framework to examine the preservation and capitalization effects of government farmland preservation policies. More specifically, emphasis is given to the effects of such policies on the number and type of land buyers, the distribution of offer price, and the mean waiting period. The results suggest that, in the context of the agricultural zoning policy, the final impact on the reservation price and mean waiting period depends on the magnitude of changes in the number and spread of the type of buyers.
\end{abstract}

JEL Codes: C7, C11, Q28, Q51

Keywords: hedonic price, Bayesian approach, farm land valuation, government farm policy 


\section{Introduction}

The question of how offer prices are formed for commodities with public goods characteristics remains to be a salient issue in the public goods literature because the market fails to determine the optimal allocation of such goods. Farmland is one such commodity with its spatial fixity, durability, and heterogeneity ( $\mathrm{Xu}$, et al., 1993), and hence the market fails to provide its optimal allocation as well. The reasons are threefold. First, spatial fixity makes it hard to protect the land against adverse external effects, calling for government intervention to avoid or reduce these effects. Second, land quality is influenced by its degree of durability, irreversibility, and renewability. Land is durable in the physical sense, however, its desirable attributes may be lost over time at a large scale unless necessary measures are taken by policy makers to preserve them. ${ }^{1}$ Third, heterogeneity limits the number and type of agents in the land market, invalidating the neoclassical assumption that agents are pricetakers.

Considering these special features of land, we seek in this study to present a hedonic price approach to modeling the private-valuation and formation of the offer price of land. Our modeling is based on the notion that land is heterogeneous in its attributes, and that the private-valuation of the

1 The reader is referred to Henneberry and Barrow (1990) and Beaton (1991) for the price effect of government interventions in farmland markets. 
attributes is the only factor that determines the offer price (e.g., $\mathrm{Xu}$, et al., 1993; Palmquist, 1989). More specifically, we assume that an individual's valuation of a parcel of land depends on the attributes of the parcel whose hedonic prices are determined only by the individual's preferences. To simplify the analysis, we further assume that hedonic prices and therefore individual valuations of land are independent across individuals.

Applying a search model in which farmers are treated as sellers in the farmland market, Tavernier and $\mathrm{Li}$ (1995) showed that government programs increasing current farm income should result in an increase in the reservation price, and hence lead to some degree of farmland preservation. Unfortunately, their approach suffers two weaknesses: first, buyers are treated as passive agents; and second, the distribution of their offer price is assumed to be exogenously given (Stern, 1990). In the present study, we try to overcome these weaknesses by modeling farmers as buyers and assuming that they have subjective beliefs about the distribution of offer prices (McCall, 1970).

In the next section we develop a bidding game to illustrate the formation of the offer price, using the concept of hedonic prices. Private information plays an important role in this price formation process, which is modeled as a Bayesian game. The offer price is based on the subjective belief of 
buyers with regard to the underlying value of farmland and the strategic behavior of others in the farmland market.

The outline of the paper is as follows. Section 2 introduces the hedonic price approach for the private valuation of farmland. A symmetric equilibrium solution for this game is derived in Section 3. In Section 4, the properties of such equilibrium are investigated. Section 5 concludes, drawing attention to the implications of the results for designing farmland preservation policies.

\section{Private Information and Valuation of Land}

A first-price bidding game, also known as a first-price sealed-bid auction, was developed by Rasmusen (1989). The Bayesian equilibrium concept is utilized in our framework as players have incomplete information (see Harsanyi, 1967-68). In this game, there are many potential buyers who simultaneously make offers to the seller of land. The seller accepts the highest bid that exceeds his reservation price.

Following Rosen (1974), nature selects a vector of land attributes, $x,(x \in \mathrm{X})$, such as lot size, distance from the city, and the variables related to the quality of land. An $(m \times 1)$ vector of the values of attributes is assumed to be in a hedonic price space. These values are common knowledge, while each player has her/his own valuation about the common value of $x$ 
drawn from a single underlying distribution. The value of land that buyer $i$ assigns, $t_{i}$, is derived from his profit (utility) maximization problem,

$$
t_{i}=h_{i}\left(x ; \alpha_{i}\right)
$$

where $h_{i}$ is buyer $i$ 's hedonic price rule, $t_{i}$ is a positive real-valued random variable. Given the vector of attributes $x$, buyer $i$ 's subjective valuation of a land parcel, $t_{i}$, only depends on his hedonic prices for $x, \alpha_{i} . \alpha_{i}$ is a $(1 \mathrm{x}$ m) hedonic price vector assumed to be private information. The pricing rule $h_{i}($.) represents the subjective valuation of the land. For simplicity, we assume one's valuation is independent of others and $h_{i}($.$) is symmetric$ across all players; that is, $h_{i}(.) \equiv h\left(x ; \alpha_{i}\right) \quad \forall_{i}$. (Notice that the rule itself is invariant across buyers but the hedonic price vector of attributes.) It is important to note that hedonic prices embody both public and private information on attributes. We assume that the impact of public and private information on the hedonic prices is independent of each other.

The game is described as follows. There are $n$ players (who are potential buyers) indexed by $i \in \mathrm{N}=\{1,2, \ldots, n\}$. Given $x$, player (buyer) $i$ forms his/her maximum offer price $t_{i}$ that belongs to a complete, separable metric space, $\mathrm{T}_{i}$, where $\mathrm{T}=\mathrm{X} \times \mathrm{T}_{1} \times \ldots \times \mathrm{T}_{n}$. Then, he/she selects an offer price $a_{i} \in \mathrm{A}_{i}$ where $A_{i}$ is a compact metric space and $A=A_{1} \times A_{2} \ldots \times A_{n}$. Player i's payoff function, $\mathrm{U}_{i}$, assumed to be a bounded and measurable function from $\mathrm{T} \times \mathrm{A}$ to $\mathrm{R}$ ( $\mathrm{R}$ is the set of real numbers) is of the form, 


$$
\mathrm{U}_{\mathrm{i}}=\left\{\begin{array}{lr}
\mathrm{t}_{\mathrm{i}}-\mathrm{a}_{\mathrm{i}} & \text { if } \\
0 & \mathrm{a}_{\mathrm{i}}>\mathrm{a}_{\mathrm{j}} \forall \mathrm{j} \neq \mathrm{i} \\
0 & \text { otherwise. }
\end{array}\right.
$$

Suppose a vector $\alpha \equiv\left(\alpha_{1}, \ldots, \alpha_{n}\right)$ is drawn from an i.i.d. distribution which is common knowledge. Let $f(x, t)$ be the joint probability density function of the random variables $t=\left(t_{1}, \ldots, t_{n}\right)$. Assuming that the vector of conditional density functions $g(. / x) \equiv\left(g\left(t_{1} / x\right) \ldots g\left(t_{n} / x\right)\right)$ and marginal density $e(x)$ are derived from $f(t, x)$ implies $f(x, t)=e(x) g(. / x)$. The functions $f(x, t)$ and $g(. / x)$ are also common knowledge.

Given $x$, the players are ordered by their maximum offer prices. From buyer $i$ 's point of view, let $y$ be the highest offer price of the $(n-1)$ players, that is, $y \geq y_{j}$ for all $j \neq i$. Then the conditional probability that this event occurs is,

(3) $\quad k(y / x)=(n-1) g(y / x)\left[\operatorname{Prob}\left(y \geq y_{j}\right.\right.$ for all $\left.\left.j \neq i\right)\right]=(n-1) g(y / x)(y / x)^{n-2}$

where $\mathrm{G}(. / x)=(y / x)$ is the $c d f$ of $g(. / x)$ and $g(0 / x)=\mathrm{G}(0 / x)=0$.

\section{The symmetric equilibrium}

A pure strategy is a measurable function, $\sigma_{i}: \mathrm{T}_{i} \rightarrow \mathrm{A}_{i}$, that is, $a_{i}=\sigma_{i}\left(t_{i}\right)$ for all $i$. Knowing $t_{i}$ and $x$, player $i$ offers a price, $a_{i}$, for the land on sale. We can write $a_{i}=\sigma\left(t_{i}\right)$ for all $i$ since the price rule is the same across players. Player $i$ will treat the highest offer $y$ of others as a random variable. His 
strategy $y_{i}$ is the best response to $y$ if it maximizes the expected payoff (for further discussion of the bid game, see chapter 11 of Rasmusen, 1989; Milgrom and Weber, 1982). Following equation (2), we write

$$
a_{i}=\sigma^{*}\left(t_{i}\right)=\underset{a_{i}}{\arg \max }\left[\left(t_{i}-a_{i}\right)_{\left\{\sigma^{*}\left(t_{j}\right)<a_{i}\right\}} \mid t_{i}\right] .
$$

An $n$-tuple of offer prices, $\left(a_{1}, \ldots, a_{n}\right)$, is an equilibrium if each offer price is a best response to that of others. The best response of player $i$ is obtained from maximizing the following expected payoff function with respect to $a_{i}$

$$
E U_{i}=\int_{0}^{t_{i}}\left(t_{i}-a_{i}\right) f\left(y / x, t_{i}\right) d y=\int_{0}^{\sigma^{-1}\left(a_{i}\right)}\left(t_{i}-a_{i}\right) d[G(y / x)]^{n-1}
$$

where $f(y / x, t)=k(y / x)$ due to the assumption of i.i.d. The inverse of the measurable function is denoted by $t_{i}=\sigma_{i}^{-1}\left(a_{i}\right)$. The first order condition (FOC) for a maximum expected payoff is

$$
0=(n-1) g\left(t_{i} / x\right)\left[G\left(t_{i} / x\right)\right]^{n-2}\left(t_{i}-a_{i}\right) \frac{\partial \sigma^{-1}\left(a_{i}\right)}{\partial a_{i}}-\int_{0}^{t_{i}} d[G(y / x)]^{n-1}
$$

Applying the derivative rule of the inverse function to the FOC yields

$$
\frac{\partial a_{i}}{\partial t_{i}}=\frac{g\left(t_{i} / x\right)}{G\left(t_{i} / x\right)}\left(t_{i}-a_{i}\right)(n-1)>0
$$

The solution to the differential equation (5) has the following general form, 


$$
\mathrm{a}(\mathrm{t})=\exp \left\{-\int(\mathrm{n}-1) \frac{\mathrm{g}\left(\mathrm{t}_{\mathrm{i}} / \mathrm{x}\right)}{\mathrm{G}\left(\mathrm{t}_{\mathrm{i}} / \mathrm{x}\right)} \mathrm{dt}_{\mathrm{i}}\right\}\left\{\int\left[(\mathrm{n}-1) \mathrm{t}_{\mathrm{i}} \frac{\mathrm{g}\left(\mathrm{t}_{\mathrm{i}} / \mathrm{x}\right)}{\mathrm{G}\left(\mathrm{t}_{\mathrm{i}} / \mathrm{x}\right)} \exp \left[\int(\mathrm{n}-1) \frac{\mathrm{g}\left(\mathrm{t}_{\mathrm{i}} / \mathrm{x}\right)}{\mathrm{G}\left(\mathrm{t}_{\mathrm{i}} / \mathrm{x}\right)} \mathrm{dt}_{\mathrm{i}}\right]\right] \mathrm{dt}_{\mathrm{i}}+\mathrm{c}\right\}
$$

The initial condition, $a(0)=0$, implies $c=0$ and $\mathrm{a}_{\mathrm{i}}=\mathrm{t}_{\mathrm{i}}-\frac{\int_{0}^{\mathrm{t}_{\mathrm{i}}}[\mathrm{G}(\mathrm{t} / \mathrm{x})]^{\mathrm{n}-1} \mathrm{dt}}{\left[\mathrm{G}\left(\mathrm{t}_{\mathrm{i}} / \mathrm{x}\right)\right]^{\mathrm{n}-1}}$. The $n$-tuple $(a, \ldots, a)$ is a symmetric Nash equilibrium where

$$
\mathrm{a}=\mathrm{t}-\frac{\int_{0}^{\mathrm{t}}[\mathrm{G}(\mathrm{s} / \mathrm{x})]^{\mathrm{n}-1} \mathrm{ds}}{[\mathrm{G}(\mathrm{t} / \mathrm{x})]^{\mathrm{n}-1}}=\sigma^{*}(t)
$$

This equation gives the equilibrium strategy, $a$, of buyer $i$ with type $t$ and his/her prior beliefs about other players' valuations, $G(t / x)$. The solution $a$ may be interpreted as an average taken with respect to a conditional distribution, $G(t)^{n-1}$. This interpretation indicates the relationship between the two random variables, $a$ and $t$, for any distribution of $t$. In particular, if $t$ is uniformly distributed, $a=t(n-1) / n$ will be uniformly distributed as well. That implies that one will never offer his maximum valuation $t$ (i.e., $t_{i}>a_{i}$ for all $\left.i\right)$. The buyer faces one kind of constraint: he can exert benefits from this auction (incentive compatibility). Individual rationality is automatically satisfied since participating in the auction is his choice. This result proves true that equilibrium strategy is an incentive compatible and individually rational outcome of the game. 


\section{Properties of Equilibrium}

The distribution of offer prices plays a crucial role in the formation of the seller's reservation price. The equilibrium offer price obtained in the previous section shows that the number of players and the distribution of $t$ affect the distribution of the equilibrium offer price, $a$. In this section we address how the number of buyers and the distribution of their hedonic land valuation, $t$, influence the distribution of offer prices and the seller's reservation price.

Equation (6) is the symmetric Nash equilibrium that assumes that the distribution of the strategies across players is identical. This equilibrium does not imply that the offer price of every player is identical because individual offer price is a function of his type. The equilibrium price will be the highest offer price. Under a monotonic mapping from $t$ to $a$, in equilibrium the land goes to the person who values it the most (see Rasmusen, 1989, p.251).

Under the symmetry assumption, the expected profit and expected offer price of a bidder are derived as follows. Using $\partial a / \partial t>0$ (from equation (5)) and $t=\sigma^{-1}(a)$, the unconditional distribution of $a$ becomes $\Phi(\mathrm{a})=\int_{0}^{\mathrm{a}} \phi\left(\mathrm{a}^{\prime}\right) \mathrm{da}^{\prime}=\mathrm{G}\left(\sigma^{-1}(\mathrm{a})\right)$ and $\phi(a)=\frac{g(t)}{\sigma^{\prime}(t)}=\frac{G\left(\sigma^{-1}(a)\right)}{(n-1)\left(\sigma^{-1}(a)-a\right)} . \quad \phi(a)$ and $\Phi(a)$ are unconditional pdf and cdf of $a$, respectively. For a winner whose 
bid is accepted, the joint pdf and cdf are respectively $f(a)=\Phi(a)^{n-1} \phi(a)=\frac{G\left(\sigma^{-1}(a)\right)^{n}}{(n-1)\left(\sigma^{-1}(a)-a\right)}$ and $\mathrm{F}(\mathrm{a})=\int_{0}^{\mathrm{a}} \mathrm{f}\left(\mathrm{a}^{\prime}\right) \mathrm{da}^{\prime}=\frac{\mathrm{G}\left(\sigma^{-1}(\mathrm{a})\right)^{\mathrm{n}}}{\mathrm{n}}$.

The expected profit of winner $i$ is, by definition, $\mathrm{E}_{\mathrm{w}}\left(\mathrm{t}_{\mathrm{i}}-\mathrm{a}_{\mathrm{i}}\right)=\int_{0}^{\infty} \int_{0}^{\mathrm{t}_{\mathrm{i}}}[\mathrm{G}(\mathrm{t})]^{\mathrm{n}-1} \mathrm{dtdG}\left(\mathrm{t}_{\mathrm{i}}\right)$ where $(t-a)$ is the payoff conditional on winning (i.e., $a_{i}>a_{j}$ for all $j$ ) and $[G(t / x)]^{n-1}$ is the probability of winning. Furthermore, the mean value theorem gives

$$
E_{w}(t-a)=\int_{0}^{\infty}[1-G(t)][G(t)]^{n-1} d t=[G(b)]^{n-1} E(t)
$$

where $0<\mathrm{b}<\infty, E(t)$ is the unconditional expectation of $t$. With the symmetry assumption, every player in the game expects to win with expected profit $\mathrm{E}_{\mathrm{w}}(\mathrm{t}-\mathrm{a})$. Then, $\mathrm{E}(\mathrm{t}-\mathrm{a})=\mathrm{E}_{\mathrm{w}}(\mathrm{t}-\mathrm{a})=\int_{0}^{\infty}[\mathrm{G}(\mathrm{t})]^{\mathrm{n}-1}[1-\mathrm{G}(\mathrm{t})] \mathrm{dt}$. The expected offer price, $\mathrm{E}(a)$, given by

$$
\mathrm{E}(\mathrm{t})-\mathrm{E}(\mathrm{t}-\mathrm{a})=\int_{0}^{\infty}[1-\mathrm{G}(\mathrm{t})]\left\{1-[\mathrm{G}(\mathrm{t})]^{\mathrm{n}-1}\right\} \mathrm{dt}=\left[1-[\mathrm{G}(\mathrm{b})]^{\mathrm{n}-1}\right] \mathrm{E}(\mathrm{t})
$$

From the distribution of $a$, and using the definition of Rothschild and Stiglitz (1970), we get the mean-preserving spread of $a$ as, $\mathrm{v}(\mathrm{a})=\int_{0}^{\mathrm{a}} \Phi\left(\mathrm{a}^{\prime}\right) \mathrm{da} \mathrm{a}^{\prime}=\int_{0}^{\sigma^{-1}(\mathrm{a})}(\mathrm{n}-1)(\mathrm{t}-\mathrm{a}) \mathrm{dG}(\mathrm{t})$. More clearly, it is equal to

$$
v(a)=\frac{n-1}{n-2}\left[1-\frac{G(c)^{n-2}}{G(t)^{n-2}}\right] \int_{0}^{\sigma^{-1}(a)} G(t) d t=\frac{n-1}{n-2}\left[1-\left[\frac{G(c)}{G(t)}\right]^{n-2}\right] v(t)
$$


where $0<c<a$. We now provide three propositions to illustrate the impact of the information structure on the distribution of the equilibrium offer price.

Proposition 1: As the number of players in the game increases, $E(a)$ and $v(a)$ will increase. As $n$ approaches infinity, $E(a)=E(t), v(a)=v(t)$.

Proof: Since $0<G(. / x)<1$, as $n$ increases, $E(a)$ will increase according to equation (8). Since $0<c<a, 0<G(c) / G(a)<1$, as $n$ increases, $v(a)$ will also increase according to equation (9). As $n$ approaches infinity, $G(. / x)^{n-1}$ and $(G(c) / G(a))^{n-2}$ approaches zero. Thus, $E(t)=E(a), v(a)=v(t)$.

Proposition 1 represents a convergence of the distribution of random variables in mean and spread: as the number of players in the game increases, seller's power in the auction increases and the probability that one can win the game with $t_{i}>a_{i}$ decreases. In other words, buyers' expected profit from this auction decreases and eventually the auction ends with $t_{i}=a_{i}$ (Satterhwaite and Williams, 1989).

Proposition 2: Given $x$, as $v(t)$ increases, $v(a)$ also increase, and $E(a)$ decreases.

Proof: From equation (9), as the mean-preserving spread of $t$ increases, the spread of $a$ also increases. The proof of the second part of the proposition needs the definition of risk from Rothschild and Stiglitz (1970). We say $G_{1}(. / x)$ is riskier than $G_{2}(. / x)$ in terms of mean-preserving 
spread, if, $\int_{0}^{s} G_{1}(t) d t \geq \int_{0}^{s} G_{2}(t) d t$, and $\int_{0}^{\infty} t d G_{1}(t)=\int_{0}^{\infty} t_{d} G_{2}(t)$. Let $f_{1}(t)=\int_{0}^{t}\left[G_{1}(s)\right]^{n-1} d s$, then $f(t)$ clearly is an increasing function. From equation (7), we have $\mathrm{E}_{1}(\mathrm{t}-\mathrm{a})=\int_{0}^{\infty} \mathrm{f}_{1}(\mathrm{t}) \mathrm{dG}_{1}(\mathrm{t})$ and $E_{2}(t-a)=\int_{0}^{\infty} f_{2}(t) d G_{2}(t)$ which imply $E_{2}(a)-E_{1}(a)=\int_{0}^{\infty} f_{1}(t) d G_{1}(t)-\int_{0}^{\infty} f_{2}(t) d G_{2}(t) \geq \int_{0}^{\infty} f_{1}(t) d G_{1}(t)-\int_{0}^{\infty} f_{1}(t) d G_{2}(t)=0$

Proposition 2 implies that as the type of players becomes more diverse, the spread of the offer price increases and the mean offer price decreases. The final impact on the reservation price depends on the magnitude of the changes in the mean and mean-preserving spread.

Proposition 3: Given $x$, increasing $E(t)$ leads to increasing $E(a)$, but v(a)

remains indeterminate.

Proof: From (8), note that as $\mathrm{E}(\mathrm{t})$ increases, $\mathrm{E}(\mathrm{a})$ also increases. From equation (9), however, one cannot determine the direction of change as $\mathrm{E}(\mathrm{t})$ increases. Proposition 3 suggests that as the mean of the type of players increases, the mean offer price increases as well, but the impact on the spread is undetermined. The final effect on the reservation price is positive if the change in mean is significant compared to the spread (Tavernier and Li 1995; Tavernier, Li, and Temel 1996). Tavernier and Li (1995) show that the mean waiting period before land is sold is a function 
of the reservation price and the distribution of the offer price. The authors demonstrate that an increasing reservation price due to changes in the distribution of offer prices impacts the mean waiting period.

\section{Implications and Conclusion}

This study develops a game-theoretic framework to examine the formation of farmland offer prices. It is shown that both the number and the type of potential buyers in farmland markets are among important factors influencing the distribution of offer prices. Therefore, the impact of government interventions in the farmland markets on the number and type of buyers should be carefully investigated.

In the context of agricultural zoning, the type and number of potential buyers is decreased because developers and speculators are precluded from the farmland market. According to the propositions derived above, as the number of buyers decrease, the mean $\mathrm{E}(\mathrm{a})$ and the spread of the offer price $\mathrm{v}(\mathrm{a})$ also decrease. The final impact of agricultural zoning on reservation price and the mean waiting period depends on the degree of government interventions. This finding supports the conclusions of Henneberry and Barrows (1990), and Beaton (1991), and of studies that argue that the equity of farmers is negatively impacted by agricultural zoning (Nelson, 1988; Adelaja et al., 1989). 
In the case of government housing subsidy, which increases the number of potential buyers in the farmland market, the results imply an increasing reservation price due to the increase in the mean offer price and the meanpreserving spread. Further findings suggest that as the spread of the type of buyers $\mathrm{v}(\mathrm{t})$ increases, the mean of the offer price decreases, while the spread of the offer price increases.

Our analysis points to some issues that might be of interest to policy makers. In particular, the zoning of farmland has two potential "negative" effects. First, zoning that restricts the number of buyers in the farmland markets depresses farmland price and at the same time provides an inadequate supply of land for housing. Thus, careful consideration must be given to policies to address the equity needs of farmers and the demand for affordable housing.

With this study we introduced a game-theoretic model to investigate the effects of specific government policies on the farmland prices. The study makes an important contribution to the literature as it opens up an avenue for empirical studies to quantify the preservation and capitalization effects of government farmland preservation policy on land prices. 


\section{Reference}

Adelaja, A.O., D.A. Derr and K. Rose-Tank. "Economic and equity implications of land-use zoning in suburban agriculture," J. Agric. Ethics 2(1989):97-112.

W. Beaton, The impact of regional land-use controls on property values: The case of the New Jersey Pinelands, Land Econ., 67, 172-194 (1991).

R. Engelbrecht-Wiggans, P. Milgrom, and R. Weber, Competitive bidding and proprietary information, J. Math. Econ., 11 161-169 (1983).

J. Harsanyi, Games with incomplete information played by Bayesian players, Management Science, 14 159-182, 320-334, 486-502 (1967-68).

D. Henneberry and R. Barrows, Capitalization of exclusive agricultural zoning into farmland prices, Land Econ., 66 249-258 (1990).

J. McCall, Economics of information and job search, Quarterly J.of Econ., 84 113-126 (1970).

P. Milgrom and R. Weber, Distributional strategies for games with incomplete information, Math. of Operation Research, 10 619-632 (1985).

P. Milgrom, "The structure of information in competitive bidding," Garland Publishing Company, New York 1979.

P. Milgrom and R. Weber, A theory of auctions and competitive bidding, Econometrica, 50 1089-1122 (1982).

A. Nelson, An empirical note on how regional urban containment policy influences an interaction between greenbelt and exurban land markets, J. Amer. Planning Assoc., 54 178-184 (1988). 
A. Nelson, Preserving prime farmland in the face of urbanization, J. Amer. Planning Assoc., 58 477-488 (1992).

New Jersey Department of Agriculture, "New Jersey Agricultural Statistics," Trenton, 1992.

R. Palmquist, Land as a differential factor of production: A hedonic model and its implications for welfare measurement, Land Econ., 65 23-28 (1989).

E. Rasmusen, "Games and information: An introduction to game theory," Basil Blackwell Inc., New York (1989).

S. Rosen, Hedonic prices and implicit markets: Product differentiation in pure competition, J. Pol. Economy, 82 34-45 (1974).

M. Rothschild and J. Stiglitz, Increasing risk I: A definition, J. Econ. Theory, 2 225-243 (1970).

M. Satterthwaite and S. Williams, The rate of convergence to efficiency in the buyer's bid double auction as the market become large, Rev. Econ. Studies, 56, 477-498 (1989).

S. Stern, The effects of firm optimizing behavior in matching models, Rev. Econ. Studies, 57, 647-660 (1990).

E. M. Tavernier and L. Farong, Effectiveness of use-value assessment in preserving farmland: A search-theoretic approach. J. Agr. and Applied Econ., 27 626-635 (1995).

E. M. Tavernier, F. Li, and T. T. Temel, Search theory, risk preference, and farmland preservation. Agricultural and Resource Economics Review (forthcoming April 1996).

W. Vickrey, Counterspeculation, auctions, and competitive sealed tenders, J. of Finance, 16, 8-37 (1961). 
F. Xu, R. Mittelhammer and P. Barkley, Measuring the contributions of site characteristics to the value of agricultural land, Land Econ., 69, 359-369 (1993). 
Table 1. Relationship between distribution of type and offer price.

\begin{tabular}{|c|c|c|}
\hline \multirow{2}{*}{$\begin{array}{l}\text { Distribution of the } \\
\text { type of buyers }\end{array}$} & \multicolumn{2}{|c|}{ Distribution of offer prices } \\
\hline & $\operatorname{MEAN}[\mathrm{E}(\mathrm{a})]$ & STD [v(a)] \\
\hline MEAN $[E(t)]$ & + & $?$ \\
\hline $\operatorname{STD}[v(t)]$ & - & + \\
\hline Number of buyers & + & + \\
\hline
\end{tabular}

